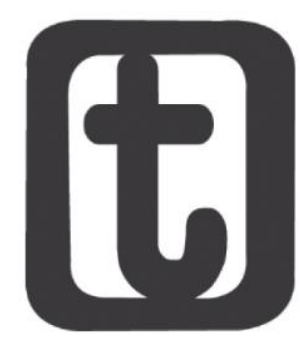

\title{
AS PARTICULARIDADES DO ENSINO SUPERIOR BRASILEIRO NOS MARCOS DO CAPITALISMO DEPENDENTE
}

The particularities of brazilian higher education in the framework of dependent capitalism

Fabiana Maria Costa*

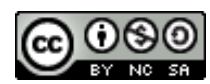

\section{RESUMO}

O trabalho discute o desenvolvimento do ensino superior no Brasil, tendo como mediações a formação social e histórica e a revolução burguesa no país e seu caráter dependente. Trata-se de uma revisão bibliográfica que recupera o desenvolvimento histórico da universidade, marcado por uma "senilização institucional precoce" e demonstra como esta foi norteada por interesses de uma burguesia conservadora, que visa à manutenção de seus privilégios e da desigualdade social, com um "caráter ultra-elitista de educação superior", de acordo com a análise de Florestan Fernandes. Assinala algumas tendências mais recentes na educação superior, que apontam para uma atualização do conservadorismo e da categoria de "reforma universitária consentida". Por fim, aponta as possibilidades de construção de hegemonia da classe trabalhadora, visto ser a universidade um âmbito de disputa ideológica, no sentido de superar sua condição de subalternidade.

\section{PALAVRAS-CHAVE}

Formação social e econômica do Brasil. Revolução burguesa. Capitalismo dependente. Universidade.

\section{ABSTRACT}

The paper discusses the development of higher education in Brazil, having as a mediation the social and historical formation and bourgeois revolution in the country and its dependent character. It is a bibliographical review that recovers the historical development of the university, marked by an "early institutional senileization" and demonstrates how it was guided by the interests of a conservative bourgeoisie, which aims to maintain its privileges and social inequality, with a "Ultra-elitist character of higher education," according to Florestan Fernandes's analysis. It points to some more recent trends in higher education, which point to an update of conservatism and the category of "college reform consented". Finally, it points out the possibilities of building hegemony of the working class, since the university is a sphere of ideological dispute, in the sense of surpassing its condition of subalternity.

\section{KEYWORDS}

Social and economic formation of Brazil. Bourgeois revolution. Higher education. Dependent capitalism. University.

\footnotetext{
* Assistente Social. Assistente social na Universidade Federal Rural de Pernambuco (UFRPE). Mestre em Serviço Social (UFPE). Doutoranda em Serviço Social pela Universidade Federal de Pernambuco (UFPE, Recife, Brasil). Av. dos Economistas, s/n, Cidade Universitária, Recife (PE), CEP.: 50670-901. E-mail: <fabiana.mkosta@gmail.com>. ORC ID: <https://orcid.org/0000-0002-2458-3795>.
} 


\section{tempordilis}

\section{INTRODUÇÃO}

No presente trabalho pretendemos realizar uma discussão, partindo da concepção da revolução burguesa no Brasil conforme Florestan Fernandes, acerca do desenvolvimento do ensino superior no país, que tem relações diretas com a forma como ocorreu a formação da burguesia no Brasil, com traços fortemente conservadores e de dependência'.

A implementação da educação superior no Brasil ocorreu de forma lenta e tardia, somente durante o século XX os cursos superiores começaram a ser instalados, a partir de 1808 com a chegada de $\mathrm{D}$. João $\mathrm{VI}^{2}$. A expansão da universidade nas primeiras décadas do século XX se relacionou com as novas demandas advindas da urbanização e da industrialização no país, o que era tomado como um passo em direção à modernidade em relação ao atraso - estrutura agrária - em que o país se encontrava.

Há, pois, um atraso na formação social burguesa no Brasil, conforme Fernandes (2006), e existia a presunção de que o esquema da Revolução Burguesa aqui seria idêntico ao das sociedades capitalistas centrais e hegemônicas, assentada na ideia de que a dependência e o subdesenvolvimento seriam estágios a serem ultrapassados. Fernandes refuta essa ideia, analisando que a expansão capitalista da parte dependente da periferia é permanentemente remodelada, de forma a manter a expropriação capitalista e o subdesenvolvimento relativo.

A revolução burguesa no Brasil, além de ter ocorrido de forma tardia, foi marcada por uma disputa entre frações da classe dominante, a oligarquia agrária e a burguesia industrial. Diferentemente do modelo clássico jacobino, aqui não houve uma ruptura radical entre as frações de classe, mas uma conciliação de interesses. Consiste, para o autor, em um fenômeno de caráter essencialmente político, "[...] de criação, consolidação e preservação de estruturas de poder predominantemente políticas, submetidas ao controle da burguesia ou por ela controláveis em quaisquer circunstâncias" (FERNANDES, 2006, p. 343).

O processo de revolução burguesa no Brasil ocorreu no momento de passagem do capitalismo competitivo ao monopolista, que teve como elemento central a industrialização e a hegemonia urbana, que aparecem como seus subprodutos, acarretando em uma intensificação na concentração de recursos materiais, humanos e técnicos nas cidades.

\footnotetext{
${ }^{1}$ Consideramos a importância dessa discussão para a categoria profissional dos assistentes sociais, pois se encontra no centro da disputa ideológica pela educação, entendida como um direito social e objeto de disputa de formação de hegemonia. Pensar a educação como dimensão da vida social, significa compreendê-la em sua relação com o trabalho, que consiste no fundamento ontológico do ser social. Assim, compreender as contradições presentes na política educacional institucionalizada sob a hegemonia do capital financeiro e reorientar a direção política da atuação profissional nesta política consiste em um desafio à profissão.

${ }^{2}$ Surgiram, então, os cursos de engenharia da Academia Real da Marinha (1808) e da Academia Real Militar (1810), o Curso de Cirurgia da Bahia (1808), de Cirurgia e Anatomia do Rio de Janeiro (1808), de Medicina (1809), também no Rio de Janeiro, de Economia (1808), de Agricultura (1812), de Química (química industrial, geologia e mineralogia), em 1817 e o Curso de Desenho Técnico (1818).
}

Temporalis, Brasília (DF), ano 18, n. 35, jan./jun. 2018. 
Desenvolvida para atender a essas necessidades, o papel da universidade brasileira esteve voltado, historicamente, aos interesses prioritários dessa burguesia, que buscava assegurar a consolidação da sua dominação, de modo a criar uma base política necessária à continuidade da transformação capitalista no país, sem ruptura com os padrões conservadores da sociedade, buscava assegurar a manutenção da imensa disparidade entre as classes.

Aprofundar tais reflexões nos auxiliará na compreensão dos efeitos da revolução burguesa dependente e conservadora sobre a universidade no Brasil, perpassada por estruturas contraditórias, que foi assumindo, durante seu desenvolvimento, características especificas em relação ao capitalismo hegemônico, ao combinar o atraso e o conservadorismo presentes na sociedade brasileira aos interesses de desenvolvimento do capitalismo dependente periférico.

Tais reflexões nos oferecem os subsídios para analisar os fenômenos mais recentes que perpassam o ensino superior no país, como a sua recente expansão mediante a lógica mercadológica, bem como os impactos provocados pelo relatório produzido pelo Banco Mundial, Um Ajuste Justo: Análise da eficiência e equidade do gasto público no Brasil, publicado em novembro de 2017, que trata das políticas públicas no Brasil, incluída a da educação superior, apontando para uma atualização do conservadorismo no ensino superior, característico da nossa formação social, ao propor a cobrança de mensalidade pelas universidades públicas.

\section{FORMAÇÃO SOCIAL BRASILEIRA E TRAÇOS CONSERVADORES DA REVOLUÇÃO BURGUESA NO BRASIL}

O descobrimento e a colonização da América ocorreram como parte de um projeto de expansão marítima de países europeus, iniciado primeiramente por Portugal, seguido pela Espanha. Esse processo surge como fruto da necessidade do expansionismo europeu, parte da acumulação capitalista em sua fase inicial, momento em que se coloca o desenvolvimento das forças produtivas, no qual as colônias americanas irão desempenhar um fundamental papel do ponto de vista das relações comerciais.

O fato de ter se constituído enquanto colônia de exploração irá demarcar a nossa formação social e histórica, tendo o país, desde o momento de sua colonização pelos europeus, assumido uma posição subalterna na divisão internacional do trabalho, voltado a fornecer bens primários necessários ao processo de expansão daqueles países colonizadores.

Prado Júnior (1970) enfatiza a relação direta existente entre o modo de propriedade no Brasil, o grande latifúndio, com a força de trabalho escrava utilizada. Para o autor, há uma continuidade na história brasileira, mesmo que com novas determinações, e não teria havido uma evolução da economia colonial para a nacional, visto que a renovação do Brasil consiste em um processo longo e não terminado, tendo como traço marcante a vasta empresa comercial, destinada a explorar os recursos naturais. 


\title{
temporalis
}

Holanda (1995) analisa as principais características da formação socioeconômica brasileira partindo de suas raízes, que carregam uma herança colonial, patrimonialista, autocrática, burguesa, estruturada a partir do sistema escravista, sob uma realidade agrária de enorme concentração fundiária, o que traz rebatimentos ainda na contemporaneidade.

A partir da herança rural, as cidades brasileiras vão se desenvolver tendo como base os domínios agrários. A passagem do capitalismo concorrencial ao monopolista provocou uma alteração nas conexões da dominação burguesa com a transformação capitalista, cujo elemento central foi a emergência da industrialização e da urbanização, necessárias à hegemonia do complexo industrial financeiro, o que transformou as relações da cidade com a economia agrária.

A burguesia brasileira urbana surge dependente em relação aos países de capitalismo hegemônico, de modo a dar continuidade às relações imperialistas, e forjada nas antigas relações senhoriais e, conforme Fernandes (2006), houve no país uma revolução inacabada, visto que a burguesia brasileira é formada por elementos arcaicos e modernos, e que a revolução burguesa no Brasil não ocorreu de maneira clássica, mas foi realizada a partir de um pacto de classes, constituindo-se em uma revolução sem ruptura.

Nessa mesma linha, Oliveira (2003) realiza uma crítica à ideia dualista presente nas análises cepalinas ${ }^{3}$ e que delas derivaram, de que havia um binômio na sociedade brasileira entre sociedade moderna e a sociedade tradicional, atrasada, baseada na ideia do subdesenvolvimento, segundo a qual o país iria se desenvolver quando deixasse para trás sua base agrícola, apresentada como sinônimo de atraso e empecilho ao desenvolvimento industrial do país. Segundo o autor:

\begin{abstract}
No plano teórico, o conceito de subdesenvolvimento como uma formação histórico-econômica singular, constituída polarmente em torno da oposição formal de um setor 'atrasado' e um setor 'moderno', não se sustenta como singularidade: esse tipo de dualidade é encontrável não apenas em quase todos os sistemas, como em quase todos os períodos. Por outro lado, a oposição na maioria dos casos é tão-somente formal: de fato, o processo real mostra uma simbiose e uma organicidade, uma unidade de contrários, em que o chamado 'moderno' cresce e se alimenta da existência do 'atrasado', se se quer manter a terminologia (OLIVEIRA, 2003, p. 32).
\end{abstract}

Há, pois, na realidade brasileira, um processo de conciliação entre o crescimento industrial a partir da Revolução de 1930 e as relações agrícolas até então estabelecidas no país. Essas, na realidade, servem de base para a acumulação primitiva necessária ao desenvolvimento industrial.

\footnotetext{
${ }^{3}$ A Comissão Econômica para a América Latina (CEPAL) foi estabelecida pela resolução 106 (VI) do Conselho Econômico e Social, de 25 de fevereiro de 1948, e começou a funcionar nesse mesmo ano. Mediante a resolução 1984/67, de 27 de julho de 1984, o Conselho decidiu que a Comissão passaria a se chamar Comissão Econômica para a América Latina e o Caribe. A CEPAL é uma das cinco comissões regionais das Nações Unidas e sua sede está em Santiago do Chile. Foi fundada para contribuir ao desenvolvimento econômico da América Latina, coordenar as ações encaminhadas à sua promoção e reforçar as relações econômicas dos países entre si e com as outras nações do mundo.
}

Temporalis, Brasília (DF), ano 18, n. 35, jan./jun. 2018. 


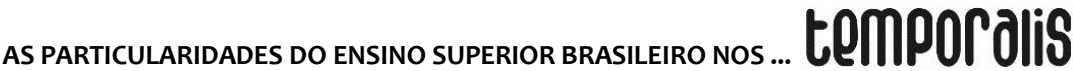

Ainda segundo o autor, a produtividade industrial brasileira cresce amparada no baixo preço da força de trabalho e na intervenção estatal, que propiciou a enorme acumulação industrial, sendo esta a raiz da tendência à concentração de renda na economia brasileira. Outro traço característico desse processo foi o fato de a constituição da industrialização ter se realizado visando atender, antes de tudo, às necessidades da acumulação e da exportação, e não as do consumo interno.

Todo esse quadro é responsável pelo estabelecimento de combinação de desigualdades na nossa realidade:

\begin{abstract}
Essa combinação de desigualdades não é original; em qualquer câmbio de sistemas ou de ciclos, ela é, antes, uma presença constante. A originalidade consistiria talvez em dizer que - sem abusar do gosto pelo paradoxo - a expansão do capitalismo no Brasil se dá introduzindo relações novas no arcaico e reproduzindo relações arcaicas no novo, um modo de compatibilizar a acumulação global, em que a introdução das relações novas no arcaico libera força de trabalho que suporta a acumulação industrial urbana e em que a reprodução de relações arcaicas no novo preserva o potencial de acumulação liberado exclusivamente para os fins de expansão do próprio novo (OLIVEIRA, 2003, p. 60, Grifos do autor).
\end{abstract}

Esse processo culminou em uma concentração de renda, de propriedade e de poder, que não foram alteradas ao longo do tempo, mas ao contrário, têm sido reatualizadas e asseveradas na contemporaneidade. A exclusão consiste, pois, em elemento vital ao dinamismo da economia brasileira.

Ao analisar a revolução burguesa no Brasil, Fernandes (2006) busca estabelecer a relação entre a transformação capitalista e a dominação burguesa em países periféricos que se inserem na economia mundial de forma dependente e subdesenvolvida, buscando compreender a especificidade da Revolução Burguesa nesse tipo de economia.

Chama a atenção para a apropriação dual do excedente econômico - internamente pela burguesia nacional e externamente pelas burguesias das nações capitalistas hegemônicas -, que provoca sérios efeitos sociais, gerando uma extrema desigualdade, com enorme concentração social da riqueza e drenagem para o exterior de grande parte do excedente econômico nacional, mantendo um rebaixamento salarial e formas de trabalho pré ou subcapitalistas. A essa modalidade de capitalismo Fernandes (2006) nomeia como selvagem, que é o capitalismo possível dentro dessa estrutura.

Há um fator essencialmente político na Revolução Burguesa brasileira, que buscou criar, consolidar e preservar estruturas de poder que garantissem a persistência da dominação burguesa e da transformação capitalista num mundo polarizado pela Guerra Fria no pós Segunda Guerra Mundial, momento em que as nações desenvolvidas passaram a depender de alianças com as burguesias nacionais de países periféricos, a fim de preservar ou consolidar o capitalismo nessas periferias, em concorrência ao perigo do socialismo hegemonizado pela União Soviética.

Como elementos responsáveis pelo caráter retardatário da Revolução Burguesa na periferia, Fernandes (2006) destaca as transformações ocorridas nas economias capitalistas centrais e hegemônicas, que esvaziaram historicamente os papéis econômicos, sociais e políticos das burguesias periféricas, as quais ficaram sem base

Temporalis, Brasília (DF), ano 18, n. 35, jan./jun. 2018. 


\title{
temporalis
}

material para concretizar tais papéis, visto o efeito das drenagens do excedente do capital nacional para os países centrais e a incorporação ao espaço econômico, cultural e político das nações imperialistas hegemônicas. Nesse sentido e a partir de tais influências, a burguesia brasileira empreendeu um processo contrarrevolucionário.

Neste contexto, a burguesia nacional pôs de lado qualquer idealismo burguês, seja reformista, liberalista ou democrático, e lançou mão do emprego da violência institucionalizada, sempre que foi necessário. Fernandes (2006) afirma ter existido uma fusão da república parlamentar com o fascismo, através do nacionalismo burguês, pois a burguesia detinha o poder econômico, social e político, possuía o controle da maquinaria do Estado nacional e contava com o suporte externo para modernizar as formas de socialização, cooptação, opressão e repressão necessárias à dominação que exercia.

A burguesia brasileira buscava, diferentemente da revolução burguesa clássica, a realização da revolução dentro da ordem, compatível com o capitalismo dependente, bem como apresentar seus interesses como se fossem os interesses gerais na nação. Seu objetivo era assegurar a consolidação da dominação burguesa no nível político, criando uma base necessária à continuidade da transformação capitalista, sob as condições e os efeitos inerentes à dupla articulação - que combina desenvolvimento desigual interno e dominação imperialista externa -, bloqueando e resistindo a qualquer pressão igualitária.

Neste sentido, a dominação burguesa serve ao desenvolvimento do capitalismo selvagem na realidade brasileira e as raízes do êxito da burguesia brasileira nesse movimento estão no amplo e dramático fenômeno de fusão dos vários estratos sociais e das várias categorias econômicas que formavam as classes possuidoras, não tendo havido na nossa realidade um verdadeiro deslocamento das velhas classes pelas novas classes sociais. Assim, a oligarquia passou por uma crise de reabsorção, fato histórico no qual se desencadeia um amplo e profundo processo de socialização do poder econômico, social e político, através do qual as classes burguesas se integraram, atualizando formas arcaicas e coloniais presentes na estrutura colonial:

\begin{abstract}
A burguesia, que fora um resíduo social e, mais tarde, um estrato pulverizado e disperso e disperso na sociedade brasileira, que se perdia nos estamentos intermediários e imitava servilmente a aristocracia, ganha sua fisionomia típica e se impõe como um corpo social organizado, que constitui a cúpula da sociedade de classes e sua grande força socioeconômica, cultural e política (FERNANDES, 2006, p. 362).
\end{abstract}

Essas são as características que dão origem à burguesia brasileira, que buscou nos elementos oligárquicos e patrimonialistas os componentes da formação do seu ethos burguês. Esses eram os limites do que poderia vir a ser e dos papéis e tarefas históricas que poderia vir a desempenhar na condição de burguesia em uma sociedade de classes subdesenvolvida e dependente no contexto do capitalismo dependente e do imperialismo.

O desenvolvimento do capitalismo interno não comportava, pois, a formação de uma burguesia que sustentasse ideias e utopias importadas da Europa e dos Estados Unidos, apesar do desenvolvimento, principalmente por parte das massas populares e dos jovens,

Temporalis, Brasília (DF), ano 18, n. 35, jan./jun. 2018. 


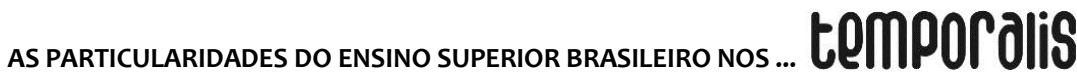

de ilusões "[...] que abriam falsas perspectivas reformistas e democráticas à revolução nacional” (FERNANDES, 2006, p. 364).

Tais reflexões nos fornecem os subsídios para compreender o desenvolvimento da educação superior pública no país, nos marcos de uma Revolução Burguesa conservadora, que sempre assegurou os interesses externos e internos, nos moldes de um capitalismo dependente e periférico na divisão internacional do trabalho.

\section{A EDUCAÇÃO SUPERIOR NO BRASIL: OS PERCURSOS HISTÓRICOS}

A educação pública no Brasil é marcada, historicamente, pela exclusão das classes subalternas, tendo sido sua constituição voltada para as elites do país. As incipientes iniciativas nesse âmbito, realizadas pelos jesuítas dos séculos XIV ao XVIII atingiam menos de $0,1 \%$ da população brasileira, visto que excluíam as mulheres, que representavam $50 \%$ da população; os escravos, $40 \%$ da população e os negros livres, os pardos, os filhos ilegítimos e as crianças abandonadas (MARCÍLIO, 2005 apud SAVIANI, 2008).

Ao período jesuíta seguiu-se às reformas pombalinas, por volta de 1772 , baseadas nas ideias laicas, inspiradas no lluminismo. Esse período foi marcado pela insuficiência de recursos por parte da Coroa, tendo em vista que a Colônia não contava com uma estrutura arrecadadora capaz de garantir a obtenção de impostos para financiar as ações educacionais.

Atravessou-se o século XIX sem que a educação pública fosse incrementada. Este quadro seguiu até a primeira república, sofrendo alterações apenas a partir da década de 1930, cenário em que a industrialização e a urbanização passaram a requisitar uma escolarização mínima por parte da classe trabalhadora.

Na mesma linha, a implementação da educação superior no país ocorreu de forma lenta e tardia. Somente durante o século XIX, os cursos superiores começaram a ser instalados no Brasil, a partir de $1808 \mathrm{com}$ a chegada de D. João VI. Eram cursos superiores isolados, não articulados no âmbito de universidades (SAVIANI, 2010).

Em 1827 são criadas as faculdades de Direito de São Paulo (SP) e de Olinda (PE). Já a criação das primeiras universidades brasileiras, que resultou do movimento de uma restrita intelectualidade nacional, ocorreu na década de 1920, a fim de modernizar o sistema educacional e seu acesso estava restrito às elites (KOWALSKI, 2012).

Conforme análise realizada por Fernandes (1975) sobre a constituição da universidade na sociedade brasileira, esta teve suas raízes históricas, culturais e pedagógicas nos modelos europeus, mais especificamente do modelo português, marcada por uma senilização institucional precoce, estando condicionada pelas limitações do sistema colonial, o que provocou alguns empobrecimentos de caráter estrutural e funcional.

Houve uma espécie de segmentação institucional, tendo em vista os interesses políticos de manutenção da dominação portuguesa, que delimitou os modelos institucionais transplantados ao Brasil, fazendo com que a política educacional fosse estreita e

Temporalis, Brasília (DF), ano 18, n. 35, jan./jun. 2018. 


\section{tempordilis}

imediatista; ao invés de universidades, foram criadas aqui faculdades e escolas superiores, caracterizando um padrão brasileiro de escola superior com um domínio de instituições não-universitárias.

Também estiveram presentes o dogmatismo religioso e tendências autoritárias em relação à liberdade intelectual, ocasionando uma modernização controlada no país, a fim de impedir um processo de autonomização cultural e o enriquecimento dos conteúdos do ensino superior, do pensamento inventivo e da modernização cultural independente.

Houve ainda uma rígida especialização unilateral, com a perspectiva de formar o letrado sem a técnica, voltada à formação de profissionais liberais, que necessitavam realizar uma complementação técnica dos estudos fora do país. Na realidade, esse tipo de formação atendia perfeitamente aos interesses imediatos da Coroa, bem como dos interesses estamentais nativos, no sentido de formar um letrado com aptidões gerais e um mínimo de informação para saber lidar com a burocracia, assegurando-lhe a manutenção do status social que possuía e graças ao qual podia acessar essa modalidade de ensino.

Desta forma, a transplantação da instituição da sociedade metropolitana esbarrava no vazio histórico criado pela própria estrutura social aqui desenvolvida, seu potencial de intervir na dinâmica cultural e intelectual fluía diretamente para as atividades liberais e suas atividades práticas, na direção da consolidação e aperfeiçoamento da ordem social existente, fundamentada na estratificação e na dominação patrimonialista dos estamentos senhoriais.

Aqui, ao contrário do que ocorria no velho mundo que já vivenciava um sistema de classes capaz de dinamizar padrões, a universidade encontrou uma sociedade fortemente estamental, cuja desagregação do regime escravista e senhorial não provocou uma ruptura com os traços de dependência econômica e cultural em relação ao exterior, mas foi marcada por um caráter ultra-eletista do ensino superior, principalmente em relação ao estrangulamento da oferta e da distribuição desigual das oportunidades educacionais.

Vale destacar que o próprio modelo de instituição português encontrava-se numa condição de considerável atraso em relação ao restante da Europa, caracterizado por um espírito retrógrado, apenas superficialmente renovado pela reforma universitária de 1772, com tendência ao verbalismo e ao dogmatismo. Nos termos de Fernandes (1975):

O 'novo' não só nascia completamente 'arcaico' - pelo menos continha um grau de obsoletização inexistente nos paradigmas explorados. Ele projetava na cena histórica brasileira como uma perene influência educacional arcaizante, que nada iria ou poderia abalar (FERNANDES, 1975, p. 98).

Uma etapa importante no ensino superior brasileiro ocorreu na passagem ao século XX, quando o país entrou em uma nova fase em seu ciclo de desenvolvimento. Mesmo sem alterar a alta concentração de renda, de prestígio social e de poder existente, a urbanização e a industrialização implicaram no estabelecimento de novas necessidades às quais o ensino superior deveria responder. 


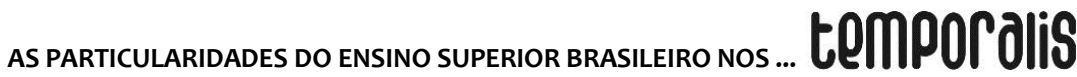

É elucidativo desse processo a criação de 64 estabelecimentos de ensino superior durante a I República (escolas superiores) e de 338 no período entre 1930 a 1960 (universidades). Essa etapa no desenvolvimento quantitativo responde às novas exigências intelectuais, sociais e culturais da civilização urbano-industrial, o que acarretou uma expansão do ensino, da ciência e da tecnologia científica, bem como uma intensificação da produção de conhecimentos originais. Fazia-se necessária a formação de uma nova mentalidade de orientação pragmática e também científica e universitária.

Apesar das novas expectativas em relação à universidade por parte da sociedade quanto à sua redefinição social e cultural, visto que o diploma não é mais perseguido somente como símbolo social, o ensino superior apenas teve suas bases reelaboradas, tendo em vista que a situação de dependência no país não foi eliminada, mas apenas foi redefinida. Assim, a universidade sofre os efeitos de uma revolução burguesa assentada no desenvolvimento dependente e não pôde ser explorada na mesma direção e maneira que as sociedades hegemônicas, estando sobremaneira fadada ao recebimento ou à cópia das inovações dos países hegemônicos.

Conforme Fernandes (1975) bem define:

O padrão brasileiro de escola superior nunca deitou raízes em concepções, processos ou valores educacionais que foram vitais para a revolução do mundo moderno, na Europa ou nos Estados Unidos. Ao contrário, ele se prendia a uma composição de resíduos educacionais ou institucionais arcaicos com interesses estamentais ou de classes, que só poderia ter algum sentido dinâmico no contexto histórico da formação do capitalismo dependente no Brasil. Não só estava montado para servir às relações de dependência; dava suporte a uma orientação tipicamente conservadora, que esvaziava a contribuição das escolas superiores para a transplantação cultural de significado histórico mais ou menos perturbador (FERNANDES, 1975, p. 108-109).

Desenvolvida sob tais parâmetros, a universidade brasileira comportou o desenvolvimento de ideias alienadas e até mesmo invertidas sobre a realidade, além disso sustentava a crença ilusória de origem cepalina de que as sociedades subdesenvolvidas superariam essa condição segundo o ciclo evolutivo das sociedades capitalistas avançadas.

$\mathrm{Na}$ realidade, tais sociedades se beneficiavam desse quadro, monopolizando o controle dos processos de invenção cultural e de desenvolvimento da civilização industrial e mantendo intactas as relações de dependência. Segundo Fernandes (1975), estas evoluíram rapidamente do neocolonialismo para o imperialismo econômico, submetendo as economias dependentes a um complexo processo de crescimento econômico controlado externamente, estando fadadas a crescer conforme os interesses e o dinamismo das sociedades hegemônicas.

Mesmo quando se tentou romper com o conservadorismo no ensino superior, o que tivemos foi uma modernização educacional conservadora, que foi encaminhada no processo de reforma universitária empreendida durante o governo autocrático burguês, selado em 1968. 
Em análise acerca da atualidade da discussão realizada por Fernandes sobre a reforma universitária, Silveira Júnior e Nascimento (2016) apontam para o caráter dependente do padrão brasileiro de escola superior no qual as determinações sócio históricas produzidas pela dinâmica do capitalismo heterônimo requisitaram uma determinada abordagem da educação. No entanto,

Era como se o avanço dessa sociedade criasse a necessidade de extensão das influências socializadoras da escola às classes subalternas, com a consequente realização de transformações substanciais nos aspectos didático-pedagógicos, enquanto o próprio sistema educacional retrógrado limitava a procura, rejeitava os candidatos à escolarização e resistia à mudança interna (SILVEIRA JÚNIOR; NASCIMENTO, 2016, p. 202).

A consolidação da sociedade urbano-industrial provocou alterações nas demandas para a educação superior. Foram também decisivas as pressões sociodinâmicas - de natureza socioeconômica ou mesmo condicionamentos de origem de coalisões políticas inerentes ao processo de consolidação do capitalismo monopolista, que encontrou obstáculos às alterações progressistas na antiquada escola superior.

A universidade, caracterizada por Fernandes como uma universidade conglomerada, visto ser formada por uma conglomeração das antigas escolas superiores, passa por um momento de crise de legitimidade e incapacidade de responder às requisições postas, tanto pelos novos ajustamentos econômicos e ideológicos provocados pelo chamado ciclo desenvolvimentista, quanto pelas reinvindicações advindas dos movimentos estudantis.

O Estado, em sua estrutura autocrática, assumiu o projeto de reforma universitária sob sua tutela, a fim de assegurar o remodelamento do ensino superior conforme os interesses elitistas e conservadores, limitando qualquer perspectiva democratizante da universidade. Nesse processo foi decisiva a influência de modelos norte-americanos, cujo cerne consistia na instituição de um modelo organizacional de universidade, caracterizando uma modernização do ensino superior, na qual foram realizadas algumas concessões às frações de classe subalternas, que não resultassem em ameaça à dominação de classe.

Silveira Júnior e Nascimento (2016) apontam para a categoria trabalhada por Fernandes (1975) de reforma universitária consentida para explicar as mudanças educacionais constrangidas e mantidas pelo circuito fechado da dependência e do desenvolvimento desigual interno, que conduziram para a estruturação e recomposição do padrão brasileiro de escola superior. Conforme os autores, Fernandes sinaliza para o movimento de continuidade na descontinuidade no padrão existente ao longo do processo e no que resultou de tal reforma.

\section{A EDUCAÇÃO SUPERIOR BRASILEIRA PÓS CONSTITUIÇÃO DE 1988 E AS TENDÊNCIAS ATUAIS}

Uma nova era se estabeleceu no Brasil no campo educacional no período da pósredemocratização. Na Constituição Federal de 1988 a educação foi estabelecida como 


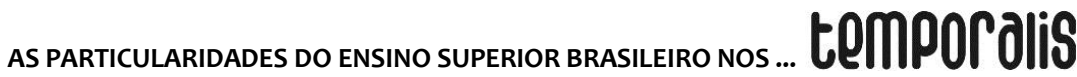

direito de todos e dever do Estado4; nos artigos 205 e 206 a igualdade de condições para o acesso e permanência na escola aparece como princípio norteador da educação no país. No entanto, a partir da década de 1990, a ofensiva neoliberal investiu contra os preceitos constitucionais e foi responsável por uma refuncionalização do Estado brasileiro, que passou a incorporar os ditames do Consenso de Washington.

Os impactos da agenda neoliberal sobre as políticas sociais se expressaram na orientação dos serviços sociais no sentido da privatização e focalização/seletividade de suas ações, incluindo-se as políticas educacionais, e, no interior delas, a instituição universidade. Estas medidas foram ganhando materialidade no processo de contrarreforma do Estado (BEHRING, 2003).

Na educação, encontramos uma forte tendência à mercantilização, com cortes no financiamento, havendo a extinção da rubrica específica que garantia o repasse financeiro às universidades públicas (LDB/1996) 5 . A própria aprovação de alterações na LDB se caracterizou, conforme Saviani (2007), adequada às reformas estruturais orientadas pelas leis do mercado.

Dando continuidade ao processo de contrarreforma da educação, o governo Lula (2003 a 2010), seguido pelo de Dilma Roussef (2011-2016), aprofundaram as ações no âmbito da educação superior, dando prosseguimento à política privatista, mesmo tendo, paradoxalmente, realizado uma ampliação e democratização do acesso.

Verifica-se, a partir de 2003, uma expansão da educação superior no Brasil, num contexto chamado de neodesenvolvimentismo ou novo desenvolvimentismo ${ }^{6}$, marcada principalmente pelo investimento massivo de recursos públicos na iniciativa privada. $\mathrm{Na}$ década de 2000, as universidades públicas vivenciaram uma intensa reestruturação, principalmente a partir da aprovação do Decreto n 6.096 de 24 de abril de 2007 (BRASIL, 2007), que instituiu o Programa de Reestruturação e Expansão das Universidades Federais (Reuni), as universidades tiveram uma expansão física vertiginosa (com a criação de novas universidades e de diversos campi avançados no interior do país), bem como uma expansão do número de vagas na graduação e na pós-graduação.

\footnotetext{
${ }^{4}$ Vale lembrar que os direitos sociais no Brasil tiveram como marco a Constituição de 1988, possível devido ao clima político da década de 1980, fundamental ao reconhecimento dos direitos sociais assegurados na Carta Constitucional e que tal conquista foi resultado de embates travados entre setores divergentes da sociedade, que buscavam assegurar seus interesses.

${ }^{5}$ A LDB de 1996 registra no artigo 71, inciso IV a desresponsabilidade do Estado com o financiamento para assistência estudantil. Segundo o referido artigo, "Não constituirão despesas de manutenção e de desenvolvimento do ensino, aquelas realizadas com: Programas suplementares de alimentação, assistência médico-odontológica, farmacêutica e psicológica, e outras formas de assistência social” (BRASIL, 1996, não paginado).

6 O novo desenvolvimentismo tem sido apontado como uma Terceira Via: "[...] uma estratégia de desenvolvimento alternativo aos modelos em vigência na América do Sul, tanto ao 'populismo burocrático', (grifos do autor) representado por setores arcaicos da esquerda e partidários do socialismo quanto à ortodoxia convencional, representada por elites rentistas e defensores do neoliberalismo [...] cujo principal objetivo é delinear um projeto nacional de crescimento econômico combinado com uma melhora substancial nos padrões distributivos do país [...] um determinado padrão de intervenção do Estado na economia e na 'questão social' (grifos do autor)" (CASTELO, 2010, apud MOTA; AMARAL; PERUZZO, 2010, p. 40).
}

Temporalis, Brasília (DF), ano 18, n. 35, jan./jun. 2018. 


\section{tempordilis}

COSTA, FABIANA MARIA

Todavia, o Reuni apresenta concepções que avançam para a construção de uma Educação Superior Pública dentro de uma lógica privada, na qual as universidades se submetem a metas mercantilizadas condicionando o financiamento de custeio e de pessoal, a uma estrutura precária nas condições de trabalho dos docentes e dos técnicoadministrativos em educação que atuam na construção do ensino, pesquisa e extensão nessas Universidades, e a uma escassez de financiamento para assistência estudantil que possibilite uma permanência de fato dos discentes nos cursos de graduação e pósgraduação.

Assim, neste contexto e sob o discurso da democratização do acesso, a reestruturação da universidade, mesmo atendendo às demandas reais por educação superior, responde às novas exigências de reprodução ampliada do capital e, com isso, serve à hegemonia burguesa e atende prioritariamente à lógica da produtividade.

Apesar do acesso à educação superior ter aumentado consideravelmente no período, segundo os dados do último Censo da Educação feito pelo INEP, o Brasil chegou em 2013 com 7,4 milhões de estudantes universitários, desse total, 5,3 milhões (73,5 \%) estão em instituições particulares. O restante se divide em instituições federais (1,1 milhão), estaduais (604 mil) e municipais (190 mil) (INEP, 2013).

Nessa lógica, merecem destaque, além do Reuni, o Programa Universidade para Todos (ProUni) e o Financiamento concedido a Estudantes do Ensino Superior Não-Gratuito Nacional (Fies). Ambos os programas, centrais no processo de contrarreforma da educação superior, preveem o repasse de vultosos volumes de recursos públicos para a iniciativa privada.

Vale atentar também ao fato de que não houve a necessária alteração na estrutura da universidade, mas a manutenção do "caráter ultra-elitista" da educação superior:

\footnotetext{
Esse caráter também persiste na ausência de mudanças substanciais na estrutura e dinâmica político-pedagógica das instituições. O acréscimo das vagas e matrículas não ocorre paralelo a alterações decisivas nos processos de ensinoaprendizagem e na estrutura organizacional das instâncias de formação - que deveriam reorganizar o ensino, a pesquisa e a extensão na perspectiva das requisições postas pelas classes subalternas provenientes do seu ingresso no ensino superior. $O$ investimento em massificação não necessariamente abole a tradicional 'tara elitista' (NETTO, 2004) da universidade brasileira (SILVEIRA JÚNIOR; NASCIMENTO, 2016, p. 213).
}

Os autores atentam para a potencialidade heurística da categoria trabalhada por Fernandes (2016) de reforma universitária consentida para apreender o caráter restritivo e conservador presente nas tentativas de reestruturação do ensino superior no Brasil contemporâneo, apontando para a manutenção e o aprofundamento do padrão educacional dependente.

Sob todo o desmonte que tem sido realizado em relação ao ensino superior no país está a defesa da lógica mercantil nessa modalidade de ensino, com a tendência de privatização tanto por meio da massificação via iniciativa privada e educação à distância, como com a

Temporalis, Brasília (DF), ano 18, n. 35, jan./jun. 2018. 


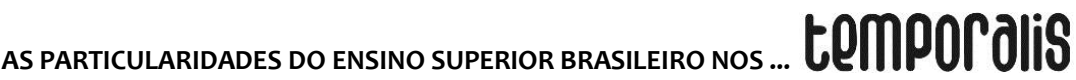

defesa da cobrança de pagamento de mensalidade por parte dos estudantes do ensino público.

O discurso em torno dessa última estratégia fica evidente nas colocações dos entes públicos, assim como pelos aparelhos privados de hegemonia:

\begin{abstract}
Para combater uma crise nunca vista, necessita-se de ideias nunca aplicadas. Neste sentido, porque não aproveitar para acabar com o ensino superior gratuito, também um mecanismo de injustiça social. Paga quem puder [...]. Funciona assim, e bem, no ensino privado (O GLOBO, 2016 apud ORSO, 2017, p. 61).
\end{abstract}

Nesta mesma linha, o então Ministro da Educação, Mendonça Filho, atendendo aos lobbies dos empresários da educação, resgatou o projeto defendido durante o governo de Fernando Henrique Cardoso (FHC) que previa a cobrança de mensalidades nas Universidades Públicas. Em audiência com dirigentes da Federação de Sindicatos de Professores e Professoras de Instituições Federais de Ensino Superior e de Ensino Básico Técnico e Tecnológico (Proifes-Federação), em 2017, a secretária executiva do ministério da Educação (MEC), Profa. Maria Helena Guimarães de Castro, defendeu veementemente a cobrança de mensalidades nas universidades e institutos federais:

\footnotetext{
Eu sou de universidade, defendo a educação pública, mas acho que temos de olhar para a situação real. Não podemos criar situações incompatíveis com o mundo que estamos vivendo, de queda de receita, de mudança no paradigma da economia do país. Nós só aumentamos em folha de pagamento (FEDERAÇÃO DE SINDICATOS DE PROFESSORES E PROFESSORAS DE INSTITUIÇÕES FEDERAIS DE ENSINO SUPERIOR E DE ENSINO BÁSICO TÉCNICO E TECNOLÓGICO, 2017, não paginado).
}

E prosseguiu: "Aliás, nem sei ainda que países têm universidades públicas plenamente gratuitas para todos, independente da situação sócio-econômica. O Brasil não pode ficar fora do mundo real" (FEDERAÇÃO DE SINDICATOS DE PROFESSORES E PROFESSORAS DE INSTITUIÇÕES FEDERAIS DE ENSINO SUPERIOR E DE ENSINO BÁSICO TÉCNICO E TECNOLÓGICO, 2017, não paginado). Contrapondo-se aos que defendem a gratuidade da graduação e da pós-graduação pública e a cobrança de mensalidades, a secretária afirmou: "Ah, mas vai ser. Sinto muito, mas vamos (cobrar mensalidades)" (FEDERAÇÃO DE SINDICATOS DE PROFESSORES E PROFESSORAS DE INSTITUIÇÕES FEDERAIS DE ENSINO SUPERIOR E DE ENSINO BÁSICO TÉCNICO E TECNOLÓGICO, 2017, não paginado). E, a fim de enfrentar as resistências, destacou: "E quando a maior universidade pública do país começar a cobrar, as outras vão cobrar, porque você quebra uma barreira" (FEDERAÇÃO DE SINDICATOS DE PROFESSORES E PROFESSORAS DE INSTITUIÇÕES FEDERAIS DE ENSINO SUPERIOR E DE ENSINO BÁSICO TÉCNICO E TECNOLÓGICO, 2017, não paginado).

Recente relatório solicitado pelo governo federal ao Banco Mundial, divulgado no dia 21 de novembro de 2017, intitulado Um ajuste justo: análise da eficiência e equidade do gasto público no Brasil, realiza uma crítica veemente aos gastos das universidades públicas, principalmente as federais, e defende a cobrança de mensalidade a fim de 'corrigir' a manutenção do elitismo nessas instituições, que estaria contribuindo com a perpetuação da desigualdade social no país. De acordo com o relatório, os gastos do governo com

Temporalis, Brasília (DF), ano 18, n. 35, jan./jun. 2018. 


\title{
temporalis
}

ensino superior são equivalentes a $0,7 \%$ do Produto Interno Bruto (PIB) e crescem, em termos reais, $7 \%$ ao ano, acima da média mundial. "As despesas com ensino superior são, ao mesmo tempo, ineficientes e regressivas" (BANCO MUNDIAL, 2017, p. 13), diz o relatório.

Os argumentos apresentados são de que a maior parte dos estudantes de nível superior está matriculada em universidades privadas no Brasil, que possuem uma melhor relação de custo-benefício e seriam mais eficientes, e os que estão nas universidades públicas são, em sua maioria, oriundos de famílias ricas.

\begin{abstract}
O ensino superior público recebe a maior parte do financiamento por aluno (aproximadamente US\$ 5 mil em PPC). Embora as matrículas no ensino superior venham subindo rapidamente no Brasil, o acesso a esse nível de ensino permanece altamente injusto. Em 2002, nenhum estudante universitário fazia parte dos $20 \%$ mais pobres da população e somente $4 \%$ integravam o grupo dos 40\% mais pobres. Em 2015, aproximadamente 15\% dos estudantes do ensino superior estavam no grupo dos 40\% mais pobres (BANCO MUNDIAL, 2017, p. 136).
\end{abstract}

A instituição defende que para cortar gastos sem prejudicar os mais pobres, o governo deveria limitar a gratuidade do ensino superior e oferecer ensino gratuito e público apenas aos estudantes que estão entre os $40 \%$ mais pobres do país. Porém, os de renda média e alta que podem pagar pelo curso depois de formados, durante a faculdade acessariam algum tipo de crédito, como o Fies.

Compreendemos que a medida consiste em um imenso retrocesso diante do processo de democratização da universidade pública e dos avanços em educação, ciência e tecnologia no país. Fere ainda o artigo 206 da Constituição Federal, o qual determina que a educação pública deve ser gratuita e responsabilidade do Estado e evidencia a adequação da educação superior brasileira aos interesses mercadológicos e privatistas do projeto do grande capital e de setores do empresariado brasileiro, ocorreria que: "[...] o privatismo patrimonialista e senhorial, iria ressurgir no privatismo individualista e empresarial" (FERNANDES, 1975, p. 129, grifos nossos).

A discussão acerca da gratuidade do ensino superior no Brasil não é algo recente e, segundo Fernandes (1975), não atende aos imperativos de democratização da educação, mas se trata de despojar o Estado brasileiro de estruturas públicas que colidam com os interesses privatistas e mercadológicos, atendendo a requisitos de um padrão de desenvolvimento econômico e cultural dependente em relação ao capitalismo mundial.

Vale ressaltar a importância da universidade pública para produção de conhecimento e desenvolvimento tecnológico, que são fundamentais à necessidade de superação da condição de dependência e subalternidade que o país possui na divisão internacional do trabalho. A produção de conhecimento científico, técnico e cultural submetido à lógica de dominação hegemônica mundial fomenta e contribui para perpetuação dessa dependência. Concordamos com Fernandes (1975) quando afirma:

Enquanto a posição hegemônica garante às nações 'centrais' um desenvolvimento cultural vantajoso, que lhes confere crescente supremacia intelectual e tecnológica, o inverso sucede com as nações 'periféricas'. Elas não

Temporalis, Brasília (DF), ano 18, n. 35, jan./jun. 2018. 


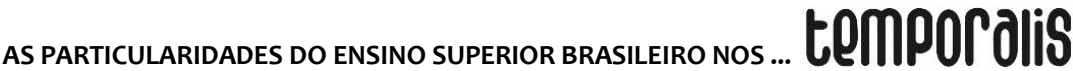

podem participar da 'corrida inventiva e criadora', ficando atreladas a um crescimento cultural reflexo e consideravelmente retardado (FERNANDES, 1975, p. 142, grifos do autor).

Democratizar o ensino superior não decorre da imperiosidade de mercantilizar o ensino oficial, com uma pretensa prática de justiça social, mas depende de que se atente para as reais necessidades educacionais da população, com uma distribuição igualitária das oportunidades educacionais, o que implicaria em uma pressão democrática a fim provocar alterações sobre a origem da desigualdade educacional.

Essa desigualdade tem sua origem na estrutura de renda, poder e prestígio social que deita raízes na formação social do Brasil. As oportunidades educacionais têm sido estabelecidas historicamente no intuito de favorecer a manutenção da hegemonia das classes sociais dominantes.

O acesso à educação e à apropriação do conhecimento significa, para a classe trabalhadora, a possibilidade de superar a condição de subalternidade e ultrapassar as restrições do cotidiano e a materialidade imediata nos limites da ordem instituída, ou do econômico-corporativo, parafraseando Gramsci. Significa ainda possibilidade de superação da ausência de autonomia, presente na condição de subalternidade, bem como conferir uma dimensão política à luta de classes, que assume cada vez mais um caráter ideológico, comprometida com transformações radicais, refletindo e criticando as contradições que perpassam as relações sociais no horizonte da formação de uma nova sociabilidade.

\section{CONSIDERAÇÕES FINAIS}

Compreendemos que se torna de fundamental importância pensar a educação enquanto elemento de hegemonia, com potencial de formação e superação de ideologias, pela importância que tem na apropriação dos códigos necessários à elaboração de projetos racionais que tencionem a ordem vigente.

Verifica-se uma preocupação da categoria profissional dos assistentes sociais, através de suas entidades representativas, na perspectiva de afirmação da concepção de educação que deve orientar a atuação profissional. Há, pois, uma articulação com o projeto ético político do serviço social, compreendendo que:

A educação pode ser considerada um espaço privilegiado para o enriquecimento ou empobrecimento do gênero humano. Assim, na perspectiva de fortalecimento do projeto ético-político, o trabalho do/a assistente social na Política de Educação pressupõe a referência a uma concepção de educação emancipadora, que possibilite aos indivíduos sociais o desenvolvimento de suas potencialidades e capacidades como gênero humano (CONSELHO FEDERAL DE SERVIÇO SOCIAL, 2013, p. 33).

Neste sentido, pensamos a universidade como enquanto instituição educadora que, mesmo imersa no contexto de elitização do saber, pela sua contradição e enquanto espaço de disputa hegemônica possui a capacidade de contribuir com a formação do pensamento autônomo das classes subalternas, condição de sua própria transformação

Temporalis, Brasília (DF), ano 18, n. 35, jan./jun. 2018. 
interna, a fim de romper com a pretensa neutralidade e com o positivismo presentes historicamente nessa instituição. A ampliação do acesso da classe trabalhadora à universidade é, pois, a condição sine qua non para a superação dos limites impostos pelo campo hegemônico dominante, no horizonte da formação de uma consciência crítica.

Somente a partir da apreensão crítica da realidade e do contexto histórico que gerou um desenvolvimento conservador e dependente, será possível à classe trabalhadora exercer pressão e controle democrático sobre a gestão do ensino superior e sobre a distribuição das oportunidades educacionais.

\section{REFERÊNCIAS}

BEHRING, E. Brasil em contrarreforma: desestruturação do Estado e perda de direitos. São Paulo: Cortez, 2003.

BRASIL. Presidência da República. Decreto n. 6.096, de 24 de abril de 2007. Institui o Programa de Apoio a Planos de Reestruturação e Expansão das Universidades Federais REUNI. Brasília (DF), 2007. Disponível em:

<http://www.planalto.gov.br/ccivil_03/_at02007-2010/2007/decreto/d6096.htm>. Acesso em: 25 nov. 2017.

BRASIL. Presidência da República. Lei nº 9. 394 de 20 de dezembro de 1996. Lei de Diretrizes e Bases da Educação Nacional - LDB. Brasília (DF), 1996.

CONSELHO FEDERAL DE SERVIÇO SOCIAL. Subsídios para a atuação de Assistentes Sociais na Política de Educação. Brochura. Brasília (DF), 2013.

FEDERAÇÃO DE SINDICATOS DE PROFESSORES E PROFESSORAS DE INSTITUIÇÕES FEDERAIS DE ENSINO SUPERIOR E DE ENSINO BÁSICO TÉCNICO E TECNOLÓGICO. Secretária do MEC defende cobrança de mensalidades. Brasília (DF), 24 mar. 2017. Disponível em: <http://www.proifes.org.br/noticias-proifes/secretaria-do-mec-defendecobranca-de-mensalidades>. Acesso em: 23 nov. 2017.

FERNANDES, F. A revolução burguesa no Brasil: ensaio de interpretação sociológica. São Paulo: Globo, 2006.

FERNANDES, F. Universidade brasileira: reforma ou revolução? São Paulo: Alfa-Omega, 1975.

KOWALSKI. Aline Viero. Os (des)caminhos da política de assistência estudantil e o desafio na garantia de direitos. Tese (Doutorado em Serviço social)- Programa de PósGraduação em Serviço Social, da Faculdade de Serviço Social da Pontifícia Universidade Católica do Rio Grande Do Sul, Porto Alegre, 2012.

HOLANDA, S. B. Raízes do Brasil. São Paulo: Companhia das Letras, 1995. 


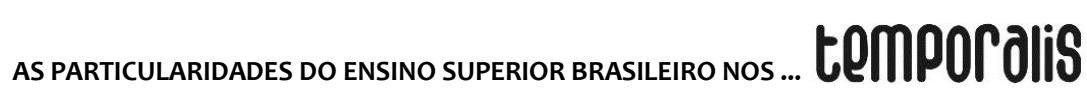

MOTA, Ana Elizabete; AMARAL, Angela Santana; PERUZZO, Juliane Feix. O novo desenvolvimentismo e as políticas sociais na América Latina. As ideologias da contrarreforma e o Serviço Social. Recife: Universidade Federal de Pernambuco, 2010.

OLIVEIRA, F. Crítica à razão dualista: o ornitorrinco. São Paulo: Boitempo, 2003.

O GLOBO. Banco Mundial recomenda fim da gratuidade nas universidades públicas. São Paulo, 21 nov. 2017. Disponível em: <https://oglobo.globo.com/economia/banco-mundialrecomenda-fim-da-gratuidade-nas-universidades-publicas-22092715>. Acesso em: 22 nov. 2017.

ORSO, P. J. A educação em tempos de golpe, ou como avançar andando para trás. Germinal: Marxismo e Educação em Debate, v. 9, n. 1, p. 50-71. Salvador, abr. 2017. Disponível em: <https://portalseer.ufba.br/index.php/revistagerminal/article/view/21735/14339>. Acesso em: 26 out. 2017 .

PRADO JÚNIOR, C. P. A formação do Brasil contemporâneo. São Paulo: Brasiliense, 1970.

SAVIANI, D. O Plano de Desenvolvimento da Educação: análise do projeto do Mec. 2007. Disponível em: <http://www.scielo.br/pdf/es/v28n100/a2728100.pdf>. Acesso em: 03 mar. 2012.

SAVIANI, D. A expansão do ensino superior no Brasil: mudanças e continuidades. Revista Poíesis Pedagógica, v. 8, n. 2, p. 4-17, ago./dez. 2010. Disponível em:

<https://www.revistas.ufg.br/poiesis/article/view/14035>. Acesso em: 25 out. 2017.

SAVIANI, D. Política educacional brasileira: limites e perspectivas. Revista de Educação PUC-Campinas. Campinas, n. 24, p. 7-16, jun. 2008.

SILVEIRA JÚNIOR. A. A.; NASCIMENTO, C. M. A crítica de Florestan Fernandes à reforma universitária e sua atualidade. Em Pauta, Rio de Janeiro, v. 14, n. 37, p. 199-216, $1^{\circ}$ semestre de 2016. Disponível em: <http://www.epublicacoes.uerj.br/index.php/revistaempauta/article/download/25398/18363>. Acesso em: 24 abr. 2018. 